\title{
Evaluation of the results of treatment of morbid obesity by the endoscopic intragastric balloon implantation method
}

\author{
Wojciech Żurawiński ${ }^{1}$, Dariusz Sokołowski ${ }^{2}$, Karolina Krupa-Kotara ${ }^{3}$, Elżbieta Czech ${ }^{4}$, Krystyn Sosada $^{1}$ \\ ${ }^{1}$ Division of Emergency Medicine, Medical University of Silesia in Katowice, Specialist Hospital No. 5 in Sosnowiec, Poland \\ ${ }^{2}$ Voivodeship Hospital, Opole, Poland \\ ${ }^{3}$ Division of Cancer Prevention, Faculty of Public Health in Bytom, Medical University of Silesia in Katowice, Poland \\ ${ }^{4}$ Department of Epidemiology and Biostatistics, Division of Biostatistics, Faculty of Public Health in Bytom, Medical University of Silesia \\ in Katowice, Poland
}

Videosurgery Miniinv 2017; 12 (1): 37-48 DOI: https://doi.org/10.5114/wiitm.2017.66856

\begin{abstract}
Introduction: Overweight and obesity are ranked in the fifth place among the risk factors responsible for the greatest number of deaths in the world.

Aim: To assess the effects of treatment of patients with morbid obesity using endoscopic intragastric balloon (IGB) implantation.

Material and methods: Two hundred and seventy-two patients with obesity were treated using endoscopic intragastric balloon implantation. Upon analysis of the inclusion and exclusion criteria, the study covered a group of 63 patients with morbid obesity. The patients were implanted with the LexBal balloon. Reduction of excess body mass, changes to BMI values and ailments and complications divided into mild and severe were assessed.

Results: Before intragastric balloon treatment, the average body mass index (BMI) value was $58.3 \pm 10.5 \mathrm{~kg} / \mathrm{m}^{2}$, whereas after 6 months of treatment it decreased to $49.5 \pm 8.7 \mathrm{~kg} / \mathrm{m}^{2}$. The patients with postoperative BMI equal to or greater than $50.0 \mathrm{~kg} / \mathrm{m}^{2}$ reported nausea (69.7\%), vomiting (51.5\%), flatulence (45.5\%), upper abdominal pain (36.4\%) and general discomfort (424\%) more frequently. Dehydration (9.1\%) was also more frequent in this group, whereas frequency of occurrence of such ailments and complications as heartburn (23.3\%) and oesophageal candidiasis (10.0\%) was higher in the patients with postoperative BMI below $50.0 \mathrm{~kg} / \mathrm{m}^{2}$.

Conclusions: Endoscopic intragastric balloon implantation is an effective and safe method of excess body mass reduction in patients with morbid obesity before a planned bariatric surgical procedure. Pre-operative excess body mass and BMI value and post-operative excess weight loss in patients with morbid obesity have no impact on frequency of occurrence of ailments and complications in IGB treatment.
\end{abstract}

Key words: morbid obesity, intragastric balloon, endoscopy.

\section{Introduction}

Obesity is a chronic disease associated with excessive accumulation of fatty tissue resulting in deteriorated quality of life, disability and increased risk of premature death. This disease of progressive na- ture displays a complex and multifactorial etiology, and its progress is influenced by both hereditary and environmental factors, including poor eating habits, decreased physical activity and stress as well as other factors, including hormonal disorders and administration of certain drugs. Simple (primary) obesity

\section{Address for correspondence}

Wojciech Żurawiński, Division of Emergency Medicine, Medical University of Silesia in Katowice, Specialist Hospital No. 5 in Sosnowiec,

Pl. Medyków 1, 41-200 Sosnowiec, Poland, phone: +48 601066 719, e-mail: w.zurawinska@wp.pl 
is caused by excessive food supply compared to energy expenditure. Obesity and associated multiple chronic conditions (MCC) represent one of the most significant issues of concern for public health of the modern world.

Overweight and obesity are ranked in the fifth position among the risk factors responsible for the greatest number of deaths in the world [1]. According to the estimates, the number of overweight people is about 1.7 billion worldwide, including about 400 million obese people [2]. According to data provided by the Central Statistical Office, excessive body weight is diagnosed in $63 \%$ of males and $46 \%$ of females in Poland. Obesity is present in $17.3 \%$ of males and $15 \%$ of females [3]. Morbid obesity occurs in $1 \%$ of the population, i.e. approximately 300000 are affected in the country [4]. The proportion of the urban population with morbid obesity may reach even 3\% [5]. According to the findings of the World Health Organization (WHO) in Geneva in 1997, obesity is diagnosed on the basis of the body mass index (BMI) when its value exceeds 30 [6]. Obesity grade 3 , i.e. morbid obesity, diagnosed when $\mathrm{BMI}$ $\geq 40 \mathrm{~kg} / \mathrm{m}^{2}$, poses a particular risk to health.

Morbid obesity is frequently associated with concomitant diseases, including hypertension, diabetes, coronary arterial disease, cholecystic diseases, hepatic fibrosis and fatty degeneration of the liver,

Table I. Indications for obesity treatment using endoscopic intragastric balloon (IGB) implantation

\begin{tabular}{|ll|}
\hline Body mass index & \multicolumn{1}{c|}{ Indications } \\
\hline$<35 \mathrm{~kg} / \mathrm{m}^{2}$ & - Diseases accompanying obesity \\
& - Ineffective conservative treatment for \\
& a period of at least 3 years \\
& - Contraindications for pharmacologi- \\
& cal obesity treatment \\
\hline$\geq 35 \mathrm{~kg} / \mathrm{m}^{2}$ & - Ineffective conservative treatment \\
& - Diseases accompanying obesity \\
& - Contraindications for bariatric sur- \\
& gical procedure or no consent of the \\
& patient for such treatment \\
& - Perioperative risk in obese patients \\
& requiring surgery, in particular \\
& bariatric, surgical, cardiosurgical and \\
& orthopaedic procedure \\
\hline$\geq 40 \mathrm{~kg} / \mathrm{m}^{2}$ & - Initial eligibility of the patients for re- \\
& strictive bariatric surgical procedure \\
& (the 'BlB test') \\
\hline$\geq 50 \mathrm{~kg} / \mathrm{m}^{2}$ &
\end{tabular}

dyslipidaemia, osteoarthritis and certain neoplasms. These diseases contribute to both significant deterioration of health condition and premature death [7]. Studies performed in a population of 900 thousand adults demonstrated that obesity reduces life expectancy by 2 to 4 years, whereas morbid obesity reduces it by up to 10 years [8].

Obesity treatment can be divided into conservative and procedural. For morbid obesity, procedural treatment is more advantageous in terms of effectiveness compared to conservative treatment [9]. One of the procedural treatment methods consists in temporary endoscopic insertion of an intragastric balloon (IGB) filled either with liquid or air into the stomach. An air- or liquid-filled balloon decreases the stomach volume by approximately $40 \%$ and distends its walls, thus inducing satiety. Continuous feeling of satiety and reducing the volume of food intake contribute to body mass reduction. The primary advantage of this method is its reversibility and low-invasive nature compared to the bariatric surgery procedures, whereas its key disadvantage is frequently impermanent loss of excess body mass. Indications for treatment of obese patients with endoscopic intragastric balloon implantation are presented in Table I [10].

The intragastric balloon is an effective method of body mass reduction in patients with morbid obesity, who due to their current health condition are ineligible for a bariatric surgical procedure lasting several hours [11]. Reduction of body weight as a result of IGB treatment has a significant impact on reducing the perioperative risks of cardiorespiratory as well as thromboembolic complications in the patients before a planned bariatric surgical procedure.

Despite improvements in the intragastric balloons, various complications in treatment of patients with obesity have been continuously described. Early complications include persistent vomiting, upper abdominal pain and gastroesophageal reflux. Late complications cover peptic ulcer and dislocation of the balloon further into the digestive tract, which in some cases leads to mechanical intestinal obstruction $[12,13]$.

The effectiveness of morbid obesity treatment using an intragastric balloon may be assessed in terms of various aspects of health and life. These include objective criteria, inter alia achieving permanent body mass reduction and recession of concomitant diseases as well as subjective criteria, including quality of life of the obese people. 
Aim

This study aims to assess the effects of treatment of patients with morbid obesity using endoscopic intragastric balloon implantation.

\section{Material and methods}

Between 1 January 2014 and 30 November 2016, 272 patients with obesity, including 212 females and 60 males, were treated using endoscopic intragastric balloon implantation in the Voivodeship Hospital in Opole. Upon analysing the inclusion and exclusion criteria, the study covered a group of 63 patients with morbid obesity treated with the IGB method. Characteristics of the studied group are presented in Table II.

\section{Study inclusion criteria}

The patients with a BMI value above $40 \mathrm{~kg} / \mathrm{m}^{2}$ were enrolled for implantation. The purpose of intragastric balloon implantation was to reduce excess body mass of the patients to improve their cardiorespiratory function and reduce the perioperative risk during the planned bariatric surgery procedure. The condition for including the patients in the procedure was complete understanding of the risk and restrictions related to surgical treatment of obesity and written consent of the patient to observe the treatment regimen in the pre- and post-operative period in force in the unit.

Eligibility criteria for treatment with the intragastric balloon also included a documented failure of the previous attempts of conservative obesity treatment and absence of psychological disorders preventing indispensable cooperation with the physician and regular outpatient follow-ups.

\section{Study exclusion criteria}

Patients with obesity caused by hormonal disorders were excluded from endoscopic treatment of morbid obesity. In addition, patients with Helicobacter pylori infection confirmed with the urease test, peptic or duodenal ulcer in the history, after gastroesophageal reflux surgery, with a potential digestive bleeding focus (oesophageal varices, telangiectases, congenital digestive anomalies), with grade 3 oesophagitis, or Barrett's oesophagus $>5 \mathrm{~cm}$ were excluded from the study. The procedure was also not performed in patients with non-specific enteritides, after digestive surgery, with cirrhosis or chronic renal insufficiency. Patients addicted to alcohol or drugs,
Table II. Characteristics of the studied group

\begin{tabular}{|c|c|c|}
\hline Studied group & $N$ & $\%$ \\
\hline Total & 63 & 100 \\
\hline \multicolumn{3}{|l|}{ Gender: } \\
\hline Female & 27 & 42.9 \\
\hline Male & 36 & 57.1 \\
\hline \multicolumn{3}{|l|}{ Age [years]: } \\
\hline $18-29$ & 6 & 9.5 \\
\hline $30-39$ & 6 & 9.5 \\
\hline $40-49$ & 20 & 31.7 \\
\hline $50-59$ & 25 & 39.7 \\
\hline $60-69$ & 6 & 9.5 \\
\hline \multicolumn{3}{|l|}{ Education: } \\
\hline Elementary & 2 & 3.2 \\
\hline Vocational & 20 & 31.7 \\
\hline Secondary & 34 & 54.0 \\
\hline Higher & 7 & 11.1 \\
\hline \multicolumn{3}{|l|}{ Professional status: } \\
\hline Pupil/student & 2 & 3.2 \\
\hline White-collar worker & 8 & 12.7 \\
\hline Blue-collar worker & 9 & 14.3 \\
\hline Unemployed & 5 & 7.9 \\
\hline Annuitant & 33 & 52.4 \\
\hline Pensioner & 7 & 11.1 \\
\hline \multicolumn{3}{|l|}{ Place of residence: } \\
\hline Rural areas & 18 & 28.6 \\
\hline City up to 50 thousand population & 12 & 19.0 \\
\hline $\begin{array}{l}\text { City between } 50 \text { and } 100 \text { thousand } \\
\text { population }\end{array}$ & 8 & 12.7 \\
\hline City above 100 thousand population & 25 & 39.7 \\
\hline
\end{tabular}

taking antithrombotic or anti-inflammatory drugs on a continuous basis, patients with AIDS, malignant tumour and pregnant females were also excluded from the procedure.

\section{Intragastric balloon implantation method}

All patients eligible for the procedure underwent the necessary laboratory tests, including blood type 
and Rh factor test, HCV, HbSAg and USR tests. The other tests included ECG, chest X-ray, spirometry with optional sleep apnoea diagnostics, abdominal ultrasound and panendoscopy with the urease test. Before the procedure, all patients were consulted by the psychologist, endocrinologist and dietary specialist. Additional consultations included laryngological and - for females - gynaecological consultations to diagnose and possibly treat any inflammatory focuses which might pose a potential source of septic complications in the postoperative period.

The patients were implanted with the LexBal balloon by Lexel Medical. The intragastric balloon insertion kit consists of a silicone catheter connected with a sheath comprising the balloon. The other end of catheter is provided with a Luer lock fitting to enable connection with the filling system. A guidewire inside the catheter facilitates insertion of the balloon into the stomach.

The balloon is implanted in a fasted patient upon sedation and local pharyngeal anaesthetics with $4 \%$ lignocaine solution using an Olympus GIF Q165 video gastroscope.

Once the balloon is deployed into the stomach, its accurate placement is assured and the balloon is filled with $0.9 \% \mathrm{NaCl}$ solution mixed with methylene blue up to the maximum total volume of $700 \mathrm{ml}$. The balloon was inflated slowly on a continuous basis to prevent high pressure in the valve. The inflated balloon should move unrestrainedly within the stomach. Then the syringe is used to generate a negative pressure in the filling catheter in order to close the

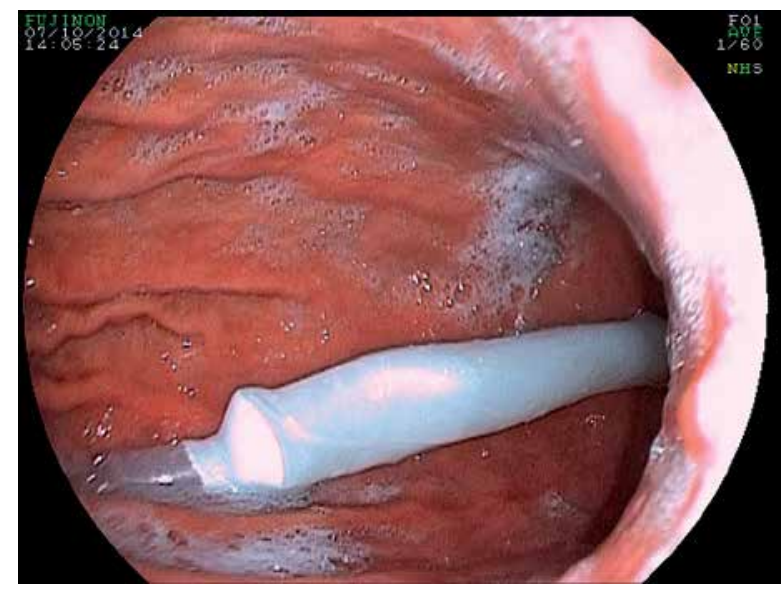

Photo 1. Balloon during inflation with physiological saline upon deployment into the stomach valve and control its tightness. The valve is not tight when, after inflating the balloon, more than $5 \mathrm{ml}$ of fluid aspirates via the catheter. Before disconnecting the catheter and removing the panendoscope, the position of the balloon, in particular against the outlet and with a view to no impaction within the stomach, is assessed (Photos 1, 2).

In the postoperative period the patients were ordered to comply with the following:

- hyoscine butylbromide $5 \mathrm{mg}$ every $6 \mathrm{~h}$ for 3 days after the procedure;

- a proton pump inhibitor, in a dose of $40 \mathrm{mg} / \mathrm{day}$ for 2 days after the procedure, followed by $20 \mathrm{mg} /$ day for 15 days;

- in case of vomiting, metoclopramide hydrochloride 60-40 mg/day;

- in case of upper abdominal pain, nonsteroidal antiinflammatory drugs;

- follow-up visits in the $1^{\text {st }}, 2^{\text {nd }}$ and $4^{\text {th }}$ week after the procedure, followed by monthly visits;

- control abdomen ultrasound in the $3^{\text {rd }}$ month after the procedure to assess the balloon volume.

In the postoperative period, the patients were obliged to observe the following dietary treatment regime:

- for the first 3 days after the procedure a liquid or semi-liquid diet, 3-4 meals a day, at least $1 \mathrm{~h}$ interval before meals, avoiding spice, coffee, sweets and cold meals. Drink $1000-1500 \mathrm{ml}$ of liquids a day.

- from the $4^{\text {th }}$ day after the procedure, gradual switching towards a solid diet. In the case of vomiting,

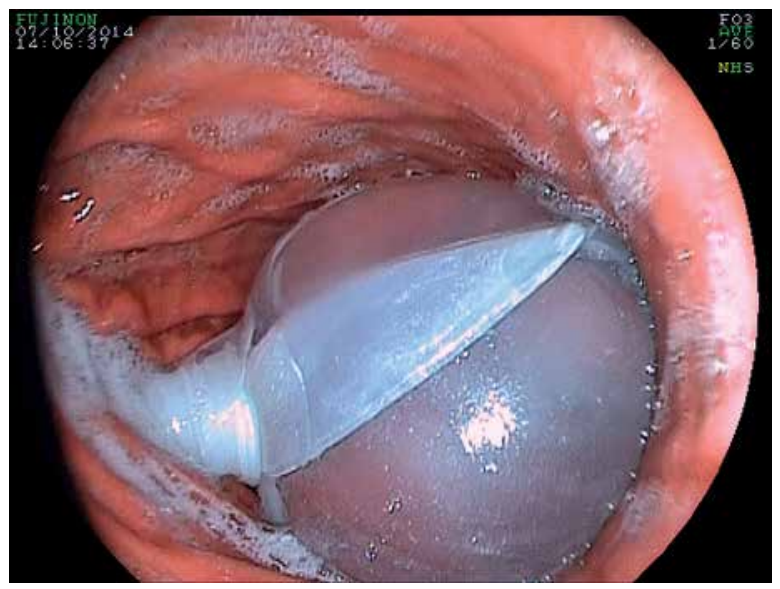

Photo 2. Balloon upon complete filling up to $700 \mathrm{ml}$ volume - controlling the balloon placement and valve tightness 
return to a semi-liquid diet for three consecutive meals. Three, four meals a day, avoiding drinking during meals, sparkling mineral water and coffee, sweets, olive oil and other high calorie meals.

\section{Intragastric balloon removal method}

The balloon was removed at 6 months after implantation. Before the procedure, the patients were ordered to switch to a liquid diet for 3 days. The balloon was removed from the stomachs of fasted and sedated patients with a panendoscope. After perforation of the balloon using a steel guidewire ended with a needle and catheter, its content was suctioned. Once the balloon was completely empty, its wall was snapped with forceps in the place opposite to the valve and removed gently from the digestive tract (Photo 3).

One of the key success criteria in obesity treatment is to reduce excess body mass. According to the International Federation for the Surgery of Obesity and Metabolic Disorders (IFSO) recommendations, body weight reduction is assessed on the basis of percentage excess weight loss (\%EWL) and differences in BMI values [14].

In treatment of patients with morbid obesity using endoscopic intragastric balloon implantation, reduction of excess body mass, changes to BMI values and afflictions and complications divided into mild and severe were assessed. Mild afflictions and complications included nausea, vomiting, upper abdominal pain lasting 2 weeks after the procedure at the latest, flatulency, gastroesophageal reflux, peptic ulcer, dehydration and general discomfort. Severe complications included complete intolerance of balloon imposing its removal, mechanical intestinal obstruction caused by clogging of the intestines by the dislocated balloon and stomach wall perforation. Afflictions and complications in the patients within the period after the endoscopic intragastric balloon implantation were analyzed depending on BMI, excess body mass and excess weight loss.

\section{Statistical analysis}

The statistical analysis was performed using the Statistica 10 software. The Shapiro-Wilk test was used to analyse data distribution. Statistical differences between variables, distribution of which was approximated to the normal distribution, were calculated with Student's t-test for dependent and inde-

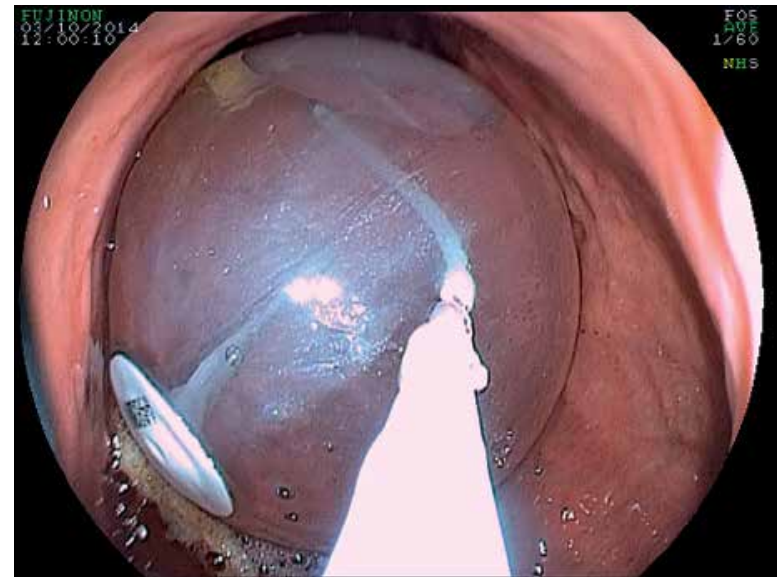

Photo 3. Intragastric balloon upon suctioning its content

pendent samples and analysis of variance (ANOVA). For variables with a distribution not compliant with the normal distribution, statistical differences were calculated with the Wilcoxon test for paired data and with the Mann-Whitney $U$ test and Kruskal-Wallis test by ranks for unpaired tests. Basic differences between frequency of occurrence of qualitative variables in the individual groups were evaluated using the $\chi^{2}$ test, Yates test or Fisher's exact test. Statistical significance was established for the value of $\alpha=0.05$.

\section{Results}

The endoscopic intragastric balloon implantation method was applied in 63 patients with morbid obesity, including 36 (57.1\%) males and 27 (42.9\%) females. Average age of the patients was $47.4 \pm 10.4$ years (females: $47.9 \pm 11.2$ years; males: $47.0 \pm 9.9$ years). The balloon was removed from the stomach after $26 \pm 2$ weeks on average.

Before intragastric balloon treatment, the average BMI value was $58.3 \pm 10.5 \mathrm{~kg} / \mathrm{m}^{2}$, whereas after 6 months of treatment it decreased to $49.5 \pm 8.7 \mathrm{~kg} /$ $\mathrm{m}^{2}$. The decrease in BMI value after 6 months of intragastric balloon treatment was $7.1 \mathrm{~kg} / \mathrm{m}^{2}(\bar{x}=8.8$ $\pm 4.9)$; in the group of male patients it was $6.9 \mathrm{~kg} / \mathrm{m}^{2}$ $(\bar{x}=8.7 \pm 5.5)$, and in the group of female patients it was $7.2 \mathrm{~kg} / \mathrm{m}^{2}(\bar{x}=8.9 \pm 4.2)$ (Table II).

A statistically significant decrease in BMI value as a result of treating the patients with morbid obesity with intragastric balloon implantation was found ( $p<0.0001$, Wilcoxon signed-rank test), both in the female group $(p<0.0001$, Wilcoxon signed- 


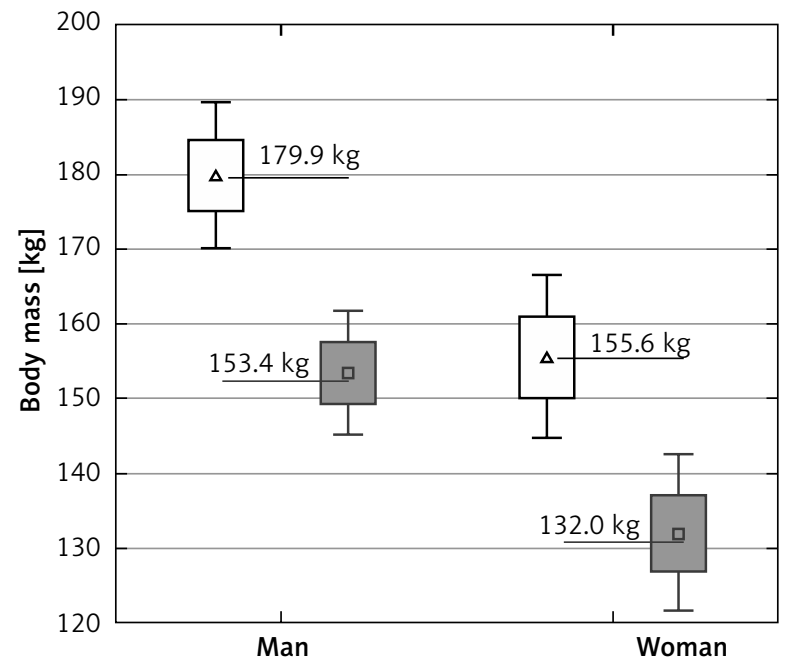

$\Delta$ Before IGB treatment

$\triangle$ Average

$\square$ Average \pm standard error

I Average \pm 0.95 confidence interval

回 After IGB treatment

$\square$ Average

$\square$ Average \pm standard error

I Average $\pm 1.96^{*}$ standard error

Figure 1. Average body mass of the patients with morbid obesity before and after 6 months of treatment with an intragastric balloon depending on sex

rank test) and the male group ( $p<0.0001$, Wilcoxon signed-rank test).

Before intragastric balloon treatment, average body mass of the patients was $169.5 \pm 30.8 \mathrm{~kg}$, whereas after 6 months of treatment it was 144.3 $\pm 27.4 \mathrm{~kg}$ (Figure 1).

Average weight loss in the treated patients was $25.2 \pm 13.5 \mathrm{~kg}$. In the female group, this value was $23.6 \pm 10.8 \mathrm{~kg}$, whereas in males it was $26.4 \pm 15.3 \mathrm{~kg}$. A statistically significant decrease of average body mass after 6 months of intragastric balloon treatment was observed ( $p<0.0001$, Student's $t$-test for dependent samples) both in females $(p<0.0001$,
Student's t-test for dependent samples) and males ( $p<0.0001$, Student's $t$-test for dependent samples).

Average value of the excess body mass (EBM) index was higher in the group of treated males (102.6 $\pm 28.2)$ than the group of females $(88.4 \pm 26.5)$ and this difference was statistically significant $(p<0.05$; Student $t$-test for independent samples).

The highest value of excess body mass was $102.5 \mathrm{~kg}$ and was found in patients aged below 30, whereas the lowest one of $65.0 \mathrm{~kg}$ was found in the group of subjects aged over 59; however, these differences are not statistically significant $(p>0.05$; Kruskal-Wallis test by ranks).

Body mass reduction (BMR) was higher in males $(23.0 \mathrm{~kg})$ than in females $(20.0 \mathrm{~kg})$, but this difference was not statistically significant $(p=0.64$; Mann-Whitney $U$ test).

The highest value of body mass reduction was recorded in patients in the age group of 30-39, whereas the lowest value applied to the patients aged 4049. Similarly as in the case of excess body mass, also the differences between the values of body mass reduction index in the age groups are not statistically significant ( $p=0.66$; Kruskal-Wallis test by ranks).

The average value of \%EWL was higher in females $(27.9 \pm 12.7 \%)$ than males $(25.7 \pm 12.0 \%)$, but this difference was not statistically significant ( $p=$ 0.49; Student's $t$-test for independent samples).

The highest value of \%EWL was recorded in patients aged 30-39, whereas the lowest value was recorded in the group of patients below 30 years of age; however, this difference was not statistically significant ( $p=0.10$; ANOVA) (Table III).

In treatment of patients with morbid obesity using the intragastric balloon implantation method, no cases of mechanical intestinal obstruction and death were recorded (Table IV).

Afflictions and complications including vomiting $(51.7 \%)$, flatulence (41.4\%), general discomfort

Table III. Body mass index value $\left[\mathrm{kg} / \mathrm{m}^{2}\right]$ in patients with morbid obesity before and after intragastric balloon treatment

\begin{tabular}{|lcccccccc|}
\hline Gender & \multicolumn{3}{c}{ BMI before treatment } & \multicolumn{5}{c|}{ BMI after treatment } \\
\cline { 2 - 9 } & Me & $\mathrm{Q}_{3}-\mathrm{Q}_{1}$ & Average & SD & Me & $\mathrm{Q}_{3}-\mathrm{Q}_{1}$ & Average & SD \\
\hline Males & 57.3 & 11.9 & 58.4 & 10.0 & 50.7 & 11.4 & 49.6 & 7.4 \\
\hline Females & 54.9 & 10.8 & 58.1 & 11.4 & 47.7 & 9.8 & 49.2 & 10.4 \\
\hline Total & 56.1 & 11.9 & 58.3 & 10.5 & 50.0 & 10.6 & 49.5 & 8.7 \\
\hline
\end{tabular}


(48.3\%), upper abdominal pain (31.0\%), heartburn (20.7\%), oesophageal candidiasis $(13.8 \%)$ and dehydration (10.3\%) were more frequently observed in the group of patients with pre-treatment BMI of $55.0 \mathrm{~kg} / \mathrm{m}^{2}$. Only nausea (64.7\%) was more frequently observed in patients with pre-treatment $\mathrm{BMI}$ of $55.0 \mathrm{~kg} / \mathrm{m}^{2}$ or above. No statistically significant differences in the frequency of occurrence of the individual afflictions or complications were found (Table V).

The patients with postoperative BMI equal to or greater than $50.0 \mathrm{~kg} / \mathrm{m}^{2}$ reported nausea (69.7\%), vomiting (51.5\%), flatulence (45.5\%), upper abdominal pain (36.4\%) and general discomfort (424\%) more frequently. Dehydration (9.1\%) was also more frequent in this group, whereas frequency of occurrence of such afflictions and complications as heartburn (23.3\%) and oesophageal candidiasis (10.0\%) was higher in the patients with postoperative BMI below $50.0 \mathrm{~kg} / \mathrm{m}^{2}$. Statistically significant differences were recorded only for frequency of nausea occurrence $(\chi=0.04 ; p=0.03)$ (Table VI).

The patients with a pre-treatment EBM index above $100 \mathrm{~kg}$ reported more frequently nausea (69.2\%) and upper abdominal pain (30.8\%), whereas heartburn (24.3\%), oesophageal candidiasis (10.8\%), dehydration (8.1\%), general discomfort (43.2\%), vomiting (48.7\%) and flatulence (43.2\%) occurred more frequently in the patients with the EBM index below $100 \mathrm{~kg}$. The differences are statistically insignificant (Table VII).

Dehydration (10.3\%), nausea (59.0\%), vomiting (51.3\%), flatulence (41.0\%) and upper abdominal pain $(33.3 \%)$ were most frequently observed in
Table IV. Ailments and complications in patients with morbid obesity in the intragastric balloon post-implantation period

\begin{tabular}{|lc|}
\hline Ailments/complications & $\begin{array}{c}\text { Number of } \\
\text { observations }\end{array}$ \\
\hline Nausea & 36 \\
\hline Vomiting & 28 \\
\hline Flatulence & 24 \\
\hline General discomfort & 24 \\
\hline Upper abdominal pain & 19 \\
\hline Heartburn & 11 \\
\hline Oesophageal candidiasis & 5 \\
\hline Dehydration & 5 \\
\hline Acute gastritis imposing balloon removal & 2 \\
\hline Self-emptying of balloon & 2 \\
\hline $\begin{array}{l}\text { Self-disconnection of catheter from } \\
\text { balloon during inflation }\end{array}$ & 1 \\
\hline
\end{tabular}

the group of patients with the post-treatment \% EWL index below 30\%, whereas general discomfort (41.7\%), heartburn (20.8\%) and oesophageal candidiasis $(8.3 \%)$ occur more frequently in the patients with the \% EWL index above $30 \%$. The differences are statistically insignificant (Table VIII).

Frequency of occurrence of any afflictions and complications in the intragastric balloon post-implantation period is higher in the patients with a pre-treatment $B M I$ value above $55.0 \mathrm{~kg} / \mathrm{m}^{2}$ and a post-treatment BMI value above $50.0 \mathrm{~kg} / \mathrm{m}^{2}$. The

Table V. Ailments and complications in patients with morbid obesity in the intragastric balloon post-implantation period depending on the body mass index (BMI) value before the procedure

\begin{tabular}{|lccccc|}
\hline Ailments/complications & \multicolumn{3}{c}{ Pre-treatment BMI $\left[\mathrm{kg} / \mathrm{m}^{2}\right]$} & \multirow{2}{*}{$\chi^{2}$ test } & \multirow{2}{*}{$P$-value } \\
\cline { 2 - 5 } & $<55.0$ & $\geq 55.0$ & Total & & 0.2 \\
\hline Nausea & $14(48.3 \%)$ & $22(64.7 \%)$ & $36(57.1 \%)$ & 1.73 & 0.3 \\
\hline Vomiting & $15(51.7 \%)$ & $13(38.2 \%)$ & $28(44.4 \%)$ & 1.15 & 0.6 \\
\hline Flatulence & $12(41.4 \%)$ & $12(35.3 \%)$ & $24(38.1 \%)$ & 0.25 & 0.1 \\
\hline General discomfort & $14(48.3 \%)$ & $10(29.4 \%)$ & $24(38.1 \%)$ & 2.36 & 0.8 \\
\hline Upper abdominal pain & $9(31.0 \%)$ & $10(29.4 \%)$ & $19(30.2 \%)$ & 0.02 & 0.5 \\
\hline Heartburn & $6(20.7 \%)$ & $5(14.7 \%)$ & $11(17.5 \%)$ & 0.39 & 0.12 \\
\hline Oesophageal candidiasis & $4(13.8 \%)$ & $1(2.9 \%)$ & $5(7.9 \%)$ & $0.12^{*}$ & 0.7 \\
\hline Dehydration & $3(10.3 \%)$ & $2(5.9 \%)$ & $5(7.9 \%)$ & $0.29^{*}$ & \\
\hline
\end{tabular}

*Fisher's test. 
Table VI. Ailments and complications in patients with morbid obesity in the intragastric balloon post-implantation period depending on the postoperative body mass index value (BMI)

\begin{tabular}{|c|c|c|c|c|c|}
\hline \multirow[t]{2}{*}{ Ailments/complications } & \multicolumn{3}{|c|}{ Postoperative BMI [kg/m²] } & \multirow[t]{2}{*}{$\chi^{2}$ test } & \multirow[t]{2}{*}{$P$-value } \\
\hline & $<50.0$ & $\geq 55.0$ & Total & & \\
\hline Nausea & $13(43.3 \%)$ & $23(69.7 \%)$ & $36(57.1 \%)$ & 0.04 & 0.03 \\
\hline Vomiting & $11(36.7 \%)$ & $17(51.5 \%)$ & $28(44.4 \%)$ & 1.40 & 0.2 \\
\hline Flatulence & $9(30.0 \%)$ & $15(45.5 \%)$ & $24(38.1 \%)$ & 1.59 & 0.2 \\
\hline General discomfort & $10(33.3 \%)$ & $14(42.4 \%)$ & $24(38.1 \%)$ & 0.55 & 0.5 \\
\hline Upper abdominal pain & $7(23.3 \%)$ & $12(36.4 \%)$ & 19 (30.2\%) & 1.27 & 0.3 \\
\hline Heartburn & $7(23.3 \%)$ & $4(12.1 \%)$ & $11(17.5 \%)$ & 1.37 & 0.2 \\
\hline Oesophageal candidiasis & $3(10.0 \%)$ & $2(6.01 \%)$ & $5(7.9 \%)$ & $0.31^{*}$ & 0.7 \\
\hline Dehydration & $2(6.7 \%)$ & 3 (9.1\%) & $5(7.9 \%)$ & $0.34^{*}$ & 1.0 \\
\hline
\end{tabular}

*Fisher's test.

Table VII. Ailments and complications in patients with morbid obesity in the intragastric balloon post-implantation period depending on pre-treatment excess body mass (EBM)

\begin{tabular}{|lccccc|}
\hline Ailments/complications & \multicolumn{3}{c}{ Pre-treatment EBM [kg] } & \multirow{2}{*}{$\chi^{2}$ test } & $P$-value \\
\cline { 2 - 5 } & $<100$ & $>100$ & $36(57.1 \%)$ & 2.64 & 0.1 \\
\hline Nausea & $18(48.7 \%)$ & $18(69.2 \%)$ & $28(44.4 \%)$ & 0.64 & 0.4 \\
\hline Vomiting & $18(48.7 \%)$ & $10(38.5 \%)$ & $24(38.1 \%)$ & 1.00 & 0.3 \\
\hline Flatulence & $16(43.2 \%)$ & $8(30.8 \%)$ & $24(38.1 \%)$ & 1.00 & 0.3 \\
\hline General discomfort & $16(43.2 \%)$ & $8(30.8 \%)$ & $19(30.2 \%)$ & $0.01^{*}$ & 0.9 \\
\hline Upper abdominal pain & $11(29.7 \%)$ & $8(30.8 \%)$ & $11(17.5 \%)$ & $0.07^{\star}$ & 0.1 \\
\hline Heartburn & $9(24.3 \%)$ & $2(7.7 \%)$ & $5(7.9 \%)$ & $0.24^{*}$ & 0.4 \\
\hline Oesophageal candidiasis & $4(10.8 \%)$ & $1(3.9 \%)$ & $5(7.9 \%)$ & $0.36^{*}$ & 1.0 \\
\hline Dehydration & $3(8.1 \%)$ & $2(7.7 \%)$ & & & \\
\hline${ }^{*}$ Fisher's test. & & & & & \\
\hline
\end{tabular}

Table VIII. Ailments and complications in patients with morbid obesity in the intragastric balloon post-implantation period depending on \%EWL

\begin{tabular}{|c|c|c|c|c|c|}
\hline \multirow[t]{2}{*}{ Ailments/complications } & \multicolumn{3}{|c|}{ Post-treatment \%EWL } & \multirow[t]{2}{*}{$\chi^{2}$ test } & \multirow[t]{2}{*}{$P$-value } \\
\hline & $>30 \%$ & $<30 \%$ & Total & & \\
\hline Nausea & $13(54.2 \%)$ & $23(59.0 \%)$ & $36(57.1 \%)$ & 0.14 & 0.7 \\
\hline Vomiting & $8(33.3 \%)$ & $20(51.3 \%)$ & $28(44.4 \%)$ & 1.94 & 0.2 \\
\hline Flatulence & $8(33.3 \%)$ & $16(41.0 \%)$ & $24(38.1 \%)$ & 0.37 & 0.5 \\
\hline General discomfort & $10(41.7 \%)$ & $14(35.9 \%)$ & $24(38.1 \%)$ & 0.21 & 0.6 \\
\hline Upper abdominal pain & $6(25.0 \%)$ & $13(33.3 \%)$ & $19(30.2 \%)$ & 0.49 & 0.5 \\
\hline Heartburn & $5(20.8 \%)$ & $6(15.4 \%)$ & $11(17.5 \%)$ & $0.23^{*}$ & 0.7 \\
\hline Oesophageal candidiasis & $2(8.3 \%)$ & $3(7.7 \%)$ & $5(7.9 \%)$ & $0.36^{\star}$ & 1.0 \\
\hline Dehydration & $1(4.2 \%)$ & $4(10.3 \%)$ & $5(7.9 \%)$ & $0.28^{*}$ & 0.6 \\
\hline
\end{tabular}


Table IX. Occurrence of any ailments and complications in patients in the intragastric balloon post-implantation period $-\chi^{2}$ test results

\begin{tabular}{|c|c|c|c|c|c|}
\hline \multirow[t]{2}{*}{ Parameter } & & \multicolumn{2}{|c|}{ Occurrence of any ailments } & \multirow[t]{2}{*}{$\chi^{2}$ test } & \multirow[t]{2}{*}{$P$-value } \\
\hline & & Yes, $n(\%)$ & No, $n(\%)$ & & \\
\hline \multirow[t]{2}{*}{ Pre-treatment BMI [kg/m²] } & $<55.0$ & $22(75.9)$ & $7(24.1)$ & \multirow[t]{2}{*}{$0.01^{*}$} & \multirow[t]{2}{*}{0.94} \\
\hline & $\geq 55.0$ & $25(73.5)$ & $9(26.5)$ & & \\
\hline \multirow[t]{2}{*}{ Post-treatment BMI $\left[\mathrm{kg} / \mathrm{m}^{2}\right]$} & $<50.0$ & $20(66.7)$ & $10(33.3)$ & \multirow[t]{2}{*}{1.90} & \multirow[t]{2}{*}{0.17} \\
\hline & $\geq 50.0$ & $27(81.8)$ & $6(18.2)$ & & \\
\hline \multirow[t]{2}{*}{ Pre-treatment EBM [kg] } & $<100$ & $27(73.0)$ & $10(27.0)$ & \multirow[t]{2}{*}{0.13} & \multirow[t]{2}{*}{0.72} \\
\hline & $\geq 100$ & $20(76.9)$ & $6(23.1)$ & & \\
\hline \multirow[t]{2}{*}{ Post-treatment \%EWL } & $<30$ & $31(79.5)$ & $8(20.5)$ & \multirow[t]{2}{*}{1.29} & \multirow[t]{2}{*}{0.26} \\
\hline & $\geq 30$ & $16(66.7)$ & $8(33.3)$ & & \\
\hline
\end{tabular}

*Yates test.

differences, however, similarly as in the case of the other indexes, are statistically insignificant (Table IX).

\section{Discussion}

The bases for attempts of intragastric balloon application in obesity treatment were provided by body mass reduction observed in patients with bezoars [15]. The first intragastric balloons in obesity treatment were applied at the beginning of the 1980s in the USA and Denmark [16, 17]. The balloons were initially inflated with air up to $220-500 \mathrm{ml}$ volume and left in the stomach for 3-4 months. Nonetheless, the therapeutic effect of the first intragastric balloons was unsatisfactory due to low mass upon inflation with air and low filling volume. Due to unsatisfactory quality of biomaterials available for balloon manufacturing, the treatment was also associated with frequent complications, including gastric mucosa perforations (3-7\%) and self-emptying of the balloon, leading to mechanical intestinal obstruction (5-11\%) [15-17].

In 1987, in Tarpon Springs (Florida) the requirements to be met by an intragastric balloon ensuring effective treatment of patients with obesity were established. One of the emphasized issues was the need for filling the balloon with liquid [18].

In 1986-1989, clinical trials using the first SIBtype liquid-filled intragastric balloon were performed in the USA [19]. In 2000-2006, effectiveness of obesity treatment with one of the most commonly used balloons in this period - the BIB (BioEnterics Intragastric Balloon) System - was studied in Brazil [20].
The scheme behind body mass loss in IGB treatment is multifactorial. Apart from reducing the stomach volume and impeding its emptying, the balloon also inhibits secretion of ghrelin, a gastric hormone increasing the appetite [21].

Balloon implantation is a safe and well-tolerated method of body mass reduction before planned surgical treatment. According to Göttig et al. [22], the number of complications after bariatric surgical procedures is lower in patients previously treated with an intragastric balloon. Pre-operative body mass loss is one of the most effective methods of perioperative risk reduction in patients with morbid obesity. Various authors state that body mass decrease upon intragastric balloon implantation ranges between 11 and $41.5 \mathrm{~kg}$. Genco et al. [23] performed a retrospective analysis of the IGB treatment results in 2515 patients with average BMI of $44.4 \mathrm{~kg} / \mathrm{m}^{2}$. After 6 months of treatment, the average BMI value was $35.4 \mathrm{~kg} / \mathrm{m}^{2}$, with an average index value drop of $4.9 \pm 12.7 \mathrm{~kg} / \mathrm{m}^{2}$, whereas the average percentage average weight loss in the studied group of patients was $33.9 \%$. Doldi et al. [13] observed body weight loss of $14 \mathrm{~kg}$ on average after 6 months of IGB method treatment in 281 patients with an average BMI of $41.8 \mathrm{~kg} / \mathrm{m}^{2}$. In the analyzed group of patients with morbid obesity, the pre-treatment BMI value was $57.7 \mathrm{~kg} / \mathrm{m}^{2}$ on average, whereas after 6 months of treatment it was $49.37 \mathrm{~kg} / \mathrm{m}^{2}$ with an average drop of $8.23 \mathrm{~kg} / \mathrm{m}^{2}$. The average decrease of BMI value in our patients was higher by $3.4 \mathrm{~kg} / \mathrm{m}^{2}$ compared to the results presented by Genco et al. [23]. Average body mass before 
treatment was $167.74 \mathrm{~kg}$, whereas after treatment it was 142.73 , which gives an average body mass loss of $25 \mathrm{~kg}$ in our patients. Mathus-Vliegen et al. [24] observed, after 6 months of IGB method treatment, body mass loss ranging between 16.7 and $20 \mathrm{~kg}$. The average value of percentage excess weight loss in our study group of patients was $25.94 \%$. Similar results were observed by Göttig et al. [22]. In 109 patients with an average BMI of $68.6 \mathrm{~kg} / \mathrm{m}^{2}$, a decrease of $8.7 \mathrm{~kg} / \mathrm{m}^{2}$ was achieved on average, with an average body mass loss of $26.3 \mathrm{~kg}$. Also Genco et al. [23] observed a body mass loss of $22.3 \mathrm{~kg}$ on average upon treatment with the IGB method. Before treatment, the average $\mathrm{BMI}$ value in the studied group was $54.1 \mathrm{~kg} / \mathrm{m}^{2}$, and average weight loss was $7.9 \mathrm{~kg} / \mathrm{m}^{2}$ after 6 months of treatment. According to other authors, the average BMI value before treatment with the IGB method was $46.7 \mathrm{~kg} / \mathrm{m}^{2}$, whereas after completion of treatment it was $43.1 \mathrm{~kg} / \mathrm{m}^{2}$, with an average BMI value decrease of $3.6 \mathrm{~kg} / \mathrm{m}^{2}$ [25].

Endoscopic intragastric balloon implantation is a low invasive method of obesity treatment. Its effectiveness and uncomplicated treatment depend on the experience of the medical professionals performing the procedure, the quality of implanted intragastric balloons and the involvement of the patient in the therapeutic process. The patient's knowledge on obesity and the applied treatment method as well as motivation to achieve the therapeutic goal and maintaining the effects after the balloon is removed are of the key importance $[26,27]$.

According to the vast majority of authors, complications in treatment of obese patients with an intragastric balloon are rare. Mild adverse reactions to the presence of an intragastric balloon include most commonly nausea, vomiting, heartburn, flatulence and contractions. Heaviness in the stomach, abdominal or back pain, gastroesophageal reflux and indigestion are usually of temporary nature and respond to conservative treatment with proton pump inhibitors, antiemetic drugs and hydration. Nonetheless, untreated and long-term vomiting may cause severe metabolic complications. Vomiting are among the most common complications after all bariatric surgical procedures, including IGB, and may occur in more than $70 \%$ of patients. Their probable causes include an unsuitable diet in the post-operative period and poor tolerance of the balloon in the stomach [28].

In the group of patients studied by us, the most common post-IGB complication was nausea (57.1\% of patients), whereas vomiting was recorded in 28 $(44.4 \%)$ patients. Balloon intolerance resulting in its removal before the end of the 6-month term was observed in two persons. In the study by Evans and Scott [29], vomiting occurred in more than a half of the patients and was the most common early complication. Complete balloon intolerance was observed by the authors in 4 patients.

One should also consider complications associated directly with endoscopy during balloon placement or removal. Hypersensitivity reaction to drugs used in analgosedation may cause severe cardiorespiratory failure. There is a high risk of aspiration during endoscopic intragastric balloon implantation, in particular in patients poorly prepared for the procedure, with the stomach filled with digestive contents [30]. Mechanical injuries of the throat, oesophagus or stomach walls may cause bleeding, oesophagitis, Malory-Weiss syndrome or even perforation requiring surgical treatment [24, 31]. Inaccurate placement of the balloon in the stomach, subject to its "impaction", and significantly reduced mobility will result in lacerations or ulcers due to mechanical pressure and irritation of the stomach walls. It may also cause stomach wall ischaemia and its perforation. Accumulation of food around the rigid valve surface in the balloon may increase local pressure on the stomach wall, forming a weakened area particularly susceptible to perforation [32]. Sudden and severe abdominal pain even several weeks or months after intragastric balloon implantation should always raise a suspicion of stomach perforation.

Balloon migration caused by its perforation or looseness leading to mechanical intestinal obstruction is a severe IGB complication [33]. According to Evans and Scott [29], in a group of 58 patients, balloon displacement was observed in 18 persons, including three who demonstrated mechanical obstruction symptoms which led to laparotomy. In 2 patients from the group treated by us, self-emptying of the balloon and its evacuation from the digestive tract without the need of surgical intervention was observed.

The study of Genco et al. [23] evaluated the effectiveness of obesity treatment with the IGB method in a group of 2515 patients. The general percentage of complications in this study was $2.8 \%$ $(n=70)$. Stomach perforation was observed in $5(0.19 \%)$ patients, including 4 who had undergone gastrotomy in the past. Two patients died. Balloon 
leakage occurred in $9(0.36 \%)$ patients. Oesophagitis was recorded in $32(1.27 \%)$ patients and peptic ulcer in $5(0.2 \%)$ patients. Mathus-Vliegen and Tygat [34] observed 3 cases of balloon intolerance (7.0\%) with oesophagitis symptoms in a group of 43 patients treated with the IGB method. Three other patients experienced gastritis as a result of administering certain nonsteroidal anti-inflammatory drugs.

The literature describes isolated cases of death of obese patients in the early endoscopic intragastric balloon post-implementation period [35].

To summarize, IGB is a good method of reducing excess body mass in patients with morbid obesity. Multicenter trials reveal however a short-term effect of body mass reduction. Therefore this method should be primarily applied in preparation of patients for a planned bariatric surgical procedure to reduce the risk of perioperative complications.

\section{Conclusions}

Endoscopic intragastric balloon implantation is an effective and safe method of excess body mass reduction in patients with morbid obesity before a planned bariatric surgical procedure. Pre-operative excess body mass and BMI value and post-operative excess weight loss in patients with morbid obesity have no impact on frequency of occurrence of afflictions and complications in the IGB treatment.

\section{Conflict of interest}

The authors declare no conflict of interest.

\section{References}

1. World Health Organization. Obesity and overweight. Fact Sheets No. 311, 2006 [accessed on: 13.12.2016 http://www.who. int/mediacentre/factsheets/fs311/en/]

2. Deitel M. Overweight and obesity worldwide now estimated to involve 1.7 billion people. Obes Surg 2003; 13: 329-30.

3. Central Statistical Office. Health condition of population in Poland in 2009. Zakład Wydawnictw Statystycznych, Warsaw 2011.

4. Stanowski E, Wyleżoł M, Paśnik K. Laparoskopia w chirurgii bariatrycznej w Polsce - stan aktualny. (Laparoscopy in bariatric surgery in Poland - current condition). Videosurgery Miniinv 2008; 3: 18-23.

5. Zejda JE, Zahorska-Markiewicz B. Epidemiologia nadwagi i otyłości w populacji aglomeracji katowickiej. (Epidemiology of excess weight and obesity in population of Katowice agglomeration). Med Metabol 2004; 8: 22.
6. World Health Organization. Department of Nutrition for Health and Development (NHD). The WHO Global Database on BMI, Geneva 2006 [accessed on: 13.12.2016 website: http://www. who.int/nmh/about/nhd/en/].

7. Rasera I Jr, Luque A, Junqueira SM Jr, et al. Effectiveness and safety of bariatric surgery in the Public Healthcare System in Brazil: real-world evidence from a high-volume obesity surgery center. Obes Surg 2017; 27: 536-40.

8. Whitlock G, Lewington S, Sherliker P, et al. Body-mass index and cause-specific mortality in 900000 adults: collaborative analyses of 57 prospective studies. Lancet 2009; 373: 1083-96.

9. Janik MR, Stanowski E, Paśnik K. Present status of bariatric surgery in Poland. Videosurgery Miniinv 2016; 11: 22-5.

10. Żurawiński W, Sosada K, Jopek J, Piecuch, et al. Endoscopic treatment of obesity with an intragastric balloon. Pol J Surg 2010; 82: 754-61.

11. De Waele B, Reynaert H, Urbain D, Willerns G. Intragastric balloons for preoperative weight reduction. Obes Surg 2000; 10: 58-60.

12. Loffredo A, Cappuccio M, De Luca M, et al. Three years experience with the new intragastric balloon, and a preoperative test for success with restrictive surgery. Obes Surg 2001; 11: 330-3.

13. Doldi SB, Micheletto G, Di Prisco F. Intragastric balloons in obese patients. Obes Surg 2000; 10: 578-81.

14. Fred M, Hainer W, Basdevant A, et al. Interdisciplinary European guidelines on surgery of severe obesity. Endokrynol Otyłość 2009; 5: 99-108

15. Nieben OG, Harboe H. Intragastric balloon as an artificial bezoar for treatment of obesity. Lancet 1982; 1: 198-9.

16. Kirby DF, Wade JB, Mills PR, et al. A prospective assessment of the Garren-Edwards gastric bubble and bariatric surgery in the treatment of morbid obesity. Am Surg 1990; 56: 575-80.

17. Meshkinpour H, Hsu D, Farivar S. Effect of gastric bubble as a weight reduction device: a controlled, crossover study. Gastroenterology 1988; 95: 589-92.

18. Schapiro M, Benjamin S, Blackburn G, et al. Obesity and the gastric balloon: a comprehensive workshop. Tarpon Springs, Florida, March 19-21, 1987. Gastrointest Endosc 1987; 33: 323-7.

19. Gau MD. Clinical trial protocol SIB-001 silicone intragastric balIoon: Final Report. INAMED March 1989.

20. Sallet JA, Marchesini JB, Paiva DS, et al. Brazilian multicenter study of the intragastric balloon. Obes Surg 2004; 14: 991-8.

21. Mion F, Napoléon B, Roman S, et al. Effects of intragastric balloon on gastric emptying and plasma ghrelin levels in non-morbid obese patients. Obes Surg 2005; 15: 510-6.

22. Göttig S, Daskalakis M, Weiner S, Weiner RA. Analysis of safety and efficacy of intragastric balloon in extremely obese patients. Obes Surg 2009; 19: 677-83.

23. Genco A, Bruni T, Doldi B, et al. BioEnterics Intragastric Balloon: the Italian experience with 2515 patients. Obes Surg 2005; 15: 1161-4.

24. Mathus-Vliegen EM, Tytgat GN. Intragastric balloon for treatment-resistant obesity: safety, tolerance, and efficacy of 1-year balloon treatment followed by a 1-year balloon-free follow-up. Gastrointest Endosc 2005; 61: 19-27.

25. Al Kahtani K, Qaseem Khan M, Helmy A, et al. Bio-enteric intragastric balloon in obese patients: a retrospective analysis of 
King Faisal Specialist Hospital experience. Obes Surg 2010; 20: 1219-26.

26. Pawlik M, Rydzewska G. Metody terapeutyczne leczenia otyłości z uwzględnieniem zastosowania balonów dożołądkowych (Therapeutic methods of obesity treatment with consideration to application of intragastric balloons). Pol Merk Lek 2009; 16 527-31.

27. MituraK, Garnysz K. Tolerance of intragastric balloon and patient's satisfaction in obesity treatment. Videosurgery Miniinv 2015; 10: 445-9.

28. Van Hout G. Psychosocial effects of bariatric surgery. Acta Chir Belg 2005; 105: 40-3.

29. Evans JD, Scott MH. Intragastric balloon in the treatment of patients with morbid obesity. Br J Surg 2001; 88: 1245-8.

30. Pretolesi F, Redaelli G, Papagni L, et al. Intragastric balloon for morbid obesity causing chronic gastric dilatation. Eur Radiol 2001; 11: 588-9.

31. Nijhof HW, Steenvoorde P, Tollenaar RA. Perforation of the oesophagus caused by the insertion of an intragastric balloon for the treatment of obesity. Obes Surg 2006; 16: 667-70.

32. Giardiello C, Cristiano S, Cerbone MR, et al. Gastric perforation in an obese patient with an intragastric balloon, following previous fundoplication. Obes Surg 2003; 13: 658-60.

33. Kim WY, Kirkpatrick UJ, Moody AP, et al. Large bowel impaction by the Bioenterics intragastric balloon necessitating surgical intervention. Ann R Coll Surg Engl 2000; 82: 202-4.

34. Mathus-Vliegen EM, Tygat GN. Gastrooesophageal reflux in obese subjects: influence of overweight, weight loss and chronic gastric balloon distension. Scand J Gastroenterol 2002; 37: $1246-52$.

35. Zheng Y, Wang M, He S, Ji G. Short-term effects of intragastric balloon in association with conservative therapy on weight loss: a meta-analysis. J Transl Med 2015; 29: 246.

Received: 5.02.2017, accepted: 15.03.2017. 